\title{
Test of a Generator in the Rumen of Cattle for Energy Harvesting to Biosensors
}

\author{
T. Reuter ${ }^{1}$, M. Beck ${ }^{1}$, S. Liebold ${ }^{1}$, M. Hoffmann ${ }^{1}$, S. Schmidt ${ }^{2}$, T. Bartsch ${ }^{2}$, P. Hörschelmann ${ }^{3}$, E. Weisheit ${ }^{3}$ \\ ${ }^{1}$ fzmb GmbH, 99947 Bad Langensalza, Germany, treuter@fzmb.de \\ ${ }^{2}$ BITSz engineering GmbH, Newtonstraße 12, 08060 Zwickau, Germany \\ ${ }^{3} \mathrm{JuB}$ - Creative Product GmbH, Industriestraße 12, 99846 Seebach, Germany
}

\begin{abstract}
Research at the fzmb GmbH is currently engaged in the development of an energy autarchic sensor system for the application in human and animal subjects [1]. The basis of the energy supply is the conversion of mechanical energy into electric energy. In this study a new energy generator is tested in the rumen of cattle. The acceleration and generated outputs depend on the motor activity of the rumen and the movement behavior of the animal.
\end{abstract}

\section{Introduction}

In the area of industrial agriculture, the systems, which deliver objective data about health, fertility, and behavioral states of livestock, are increasingly asked for. The acceptance of such systems is basically dependent on their practical applicability. In this context the energy supply is an exceptionally critical point. Hence, topical research projects at the fzmb GmbH deal with the development of an energy autarchic sensor system for the application in human and animal subjects [1]. An energy generator was developed which is able to provide energy for sensors and telemetry systems from the kinetic energy of animals and humans. The test of the energy generator was carried out in the rumen of cattle in this study. The acquired power data serves as the first evaluation for the support of the energy supply of Lowpower applications. Lowpower applications discussed here would be sensors for physiological parameters and short distance telemetry.

\subsection{Energy Harvesting}

The production tiny amounts of electric energy from resources like surroundings temperature, vibration or airstream for mobile devices with low achievement is called Energy Harvesting [2].

According to the form of energy, different physical effects are available for the Energy Harvesting. Image 1 gives an overview about the essential forms of energy and the possible physical effects.

\begin{tabular}{|l|l|}
\hline Forms of energy & Physical effects \\
\hline Kinetic & $\begin{array}{l}\text { Faraday induction } \\
\text { Piezoelectric and pyroelectric effect } \\
\text { law of electrostatic attraction (Coulomb's law) }\end{array}$ \\
\hline Thermal & Seebeck and Peltier effect \\
\hline Photonic & Photo effect \\
\hline Chemical & Electrochemical catalytic oxidation \\
\hline
\end{tabular}

Image 1 Overview about essential forms of energy and physical effects $[2,3]$
The basis of the energy autarchic sensor system to be developed here is the conversion of mechanical into electric energy by means of a generator, which is based on the principle of the faraday induction. Integral for the generation of power outputs are the accelerations appearing in the rumen or to subjects.

\subsection{Animal and rumen movement}

The steadily improving holding conditions of livestock makes it possible for cattle to move freely in pastures or stalls without the use of tie stalls.

The anatomical organization of the gastrointestinal tract (GIT) of todays ruminants represents the result of a long adaptation process to feed rich in cellulose. Ruminants developed in the course of evolution a pre-stomach system consisting of fermentation chambers in which protozoans, bacteria and mushrooms unlock the feed under anaerobic conditions. Functionally, bonnet and rumen form a unit called Reticulorumen. An important condition for actual microbial digestive processes is the constant mixing of the Ingesta in the Reticulorumen. The contraction of the rumen file makers, which rise as strong muscle bulges far back in the lumen of the rumen, allows a more intensive circulation of the Ingesta in the pre-stomach. After swallowing, the roughly chewed feed is pushed by the bonnet rumen motor activity dorsally and is in a thick mat of roughly structured feed in the dorsal rumen bag. The rumination leads to the decrease of the particle size and increase of the particle density. The extensively chopped up particles precipitate bit by bit in the ventral rumen bag. The particles reach the rumen forecourt and afterwards in the bonnet due to the contraction of the ventral rumen bag. The contraction of the individual segments of the pre-stomach must run off in a coordinated sequence in order to fulfill their function. The prestomach motor activity allows a more intensive mixing of the Ingesta, the delivery of the rumen gases (Ruktus) around the regulated wide transport of Ingesta from the Reticulorumen in the Psalter (omasum). In a healthy animal about three contractions take place within 
two minutes. During the administration of feed the frequency is nearly twice as high $[4,5]$.

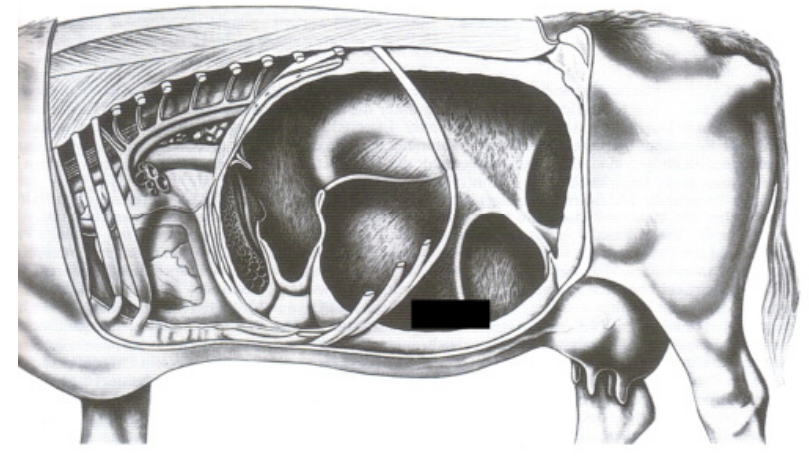

Image 2 Rumen of cattle [6] with the position of the Pansenbolus (black bar)

\section{Methods}

In the following segments the function of the energy generator, the experimental approach and the calculation for the generated power output are explained.

\subsection{Function of the Energy Generator}

The function of the generator is based on the application of a rotational pendulum, in which energy is stored in a spring mechanism, which in turn is transferred to the generator through a torque-controlled coupling. In image 4, the construction drawing of the energy generator is shown in the form of a Pansenbolus. Since the kinetic energy generated from person or animal is distributed with regard to amount and direction by chance, an adjustment gear system was developed. This adjustment gear system uses movement impulses of both rotation directions to wind up the wrap spring in order to use the largest amount of kinetic energy possible. To use the relatively narrow speed area in which the generator has a good efficiency, a wrap spring mechanism was developed.

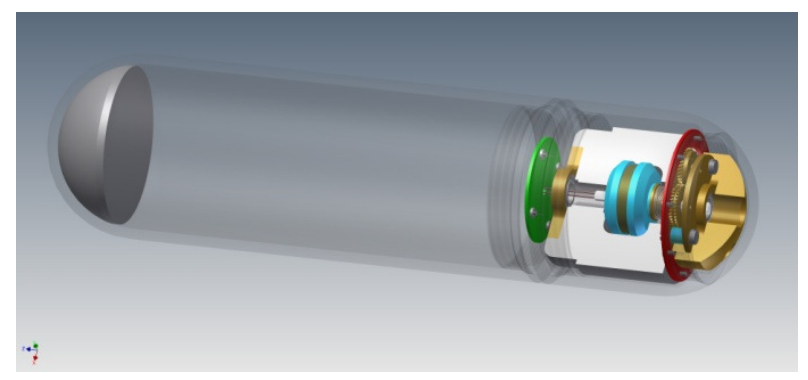

Image 4 Construction representation of the energy generator in the form of a Pansenbolus

This arrangement permits the transference of the total built up spring tension while remaining in the optimum speed area. Used as the generator is a permanent-magnet excited synchronous machine.

\subsection{Experimental Setup}

The acceleration recordings in $\mathrm{x}-, \mathrm{y}-$ and $\mathrm{z}$ - direction were taken with the data logger MSR ${ }^{\circledR} 145$ from MSR Electronics $\mathrm{GmbH}$ with a sample rate of $2 \mathrm{~Hz}$. The data recorder was fastened in a cylinder-shaped case in the form of a Pansenbolus and was given through a fistula in the rumen of cattle (Image 5).

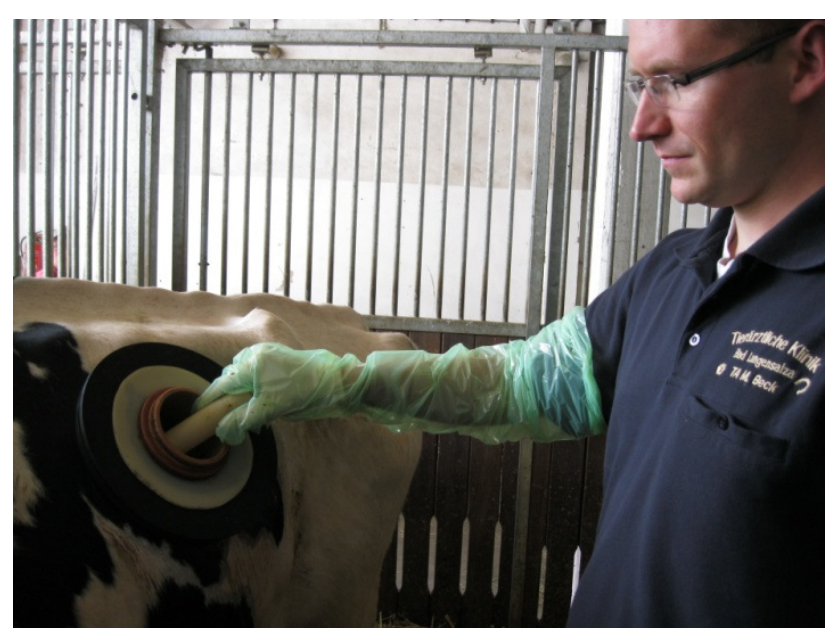

Image 5 Input of the Pansenbolus about the fistula

The form of the Pansenbolus resembles in view of the later perorale application the rumen cage magnets used in the cattle practice. The dimensions of the Pansenbolus were 35 $\mathrm{mm}$ in diameter and $140 \mathrm{~mm}$ in length. The acceleration data were recorded within a test time of $25 \mathrm{~h}$ (study A), 3 days (study B) and 4 days (study C).

The generator was also fastened to the case mentioned above and the power output was recorded. With the help of a special detection mechanism from the company BITSz engineering $\mathrm{GmbH}$, the generator discharge was recorded. The Pansenbolus (cylinder-shaped case and acceleration sensor or energy generator) had a density of $2.3 \mathrm{~g} / \mathrm{cm}^{3}$, which made sure that the Pansenbolus, was only in the ventral rumen bag (Image 2).

\subsection{Calculation of the generated power outputs}

The calculation of the generated power output $\mathrm{P}$ in $\mathrm{mW}$ was derived according to the following equation:

$$
\mathrm{P}=\mathrm{W}^{*} \mathrm{a} / \mathrm{t}
$$

W corresponds to the energy amount (work) that the generator delivers per discharge, which was determined by means of preliminary investigations and amounts to $3.3 \mathrm{mWs}$ per discharge. The parameter, a, gives the number of discharges per hour when $\mathrm{t}$ is set to $3600 \mathrm{~s}$. 


\section{Results}

The following images show the acceleration in $\mathrm{x}-, \mathrm{y}-$ and $\mathrm{z}$ - direction for study A, B and C.

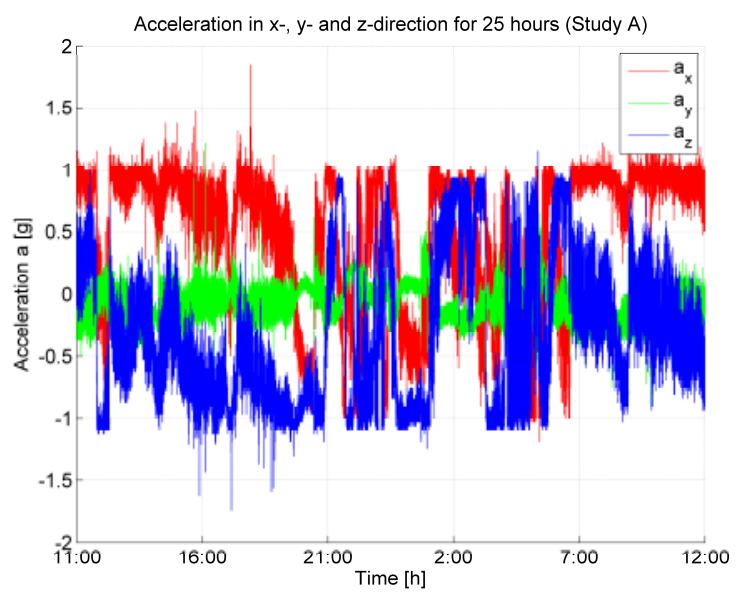

Image 6 Measurements of the acceleration study A (25h)

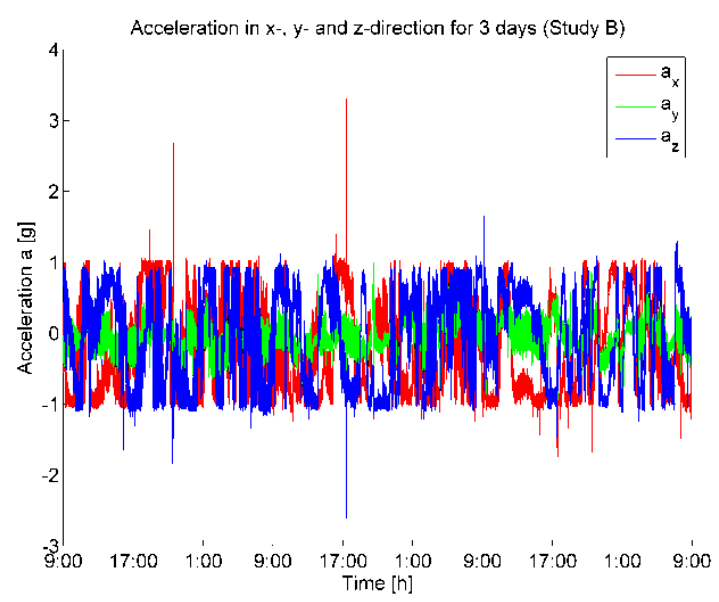

Image 7 Measurements of the acceleration study B (3 days)

The average acceleration amounted to $9.03 \mathrm{~m} / \mathrm{s}^{2}$ (study A), to $8.76 \mathrm{~m} / \mathrm{s}^{2}$ (study B) and to $8.82 \mathrm{~m} / \mathrm{s}^{2}$ (study C).

The movement of the Pansenbolus was caused by the movement behaviour of the animal, i.e. running, rising, laying down etc. as well as the intrinsic motor activity of the rumen. From the acceleration data arose big acceleration changes that appeared particularly in $\mathrm{x}-$ and $\mathrm{z}$ - direction. In y - direction, however, only minimal changes were registered.

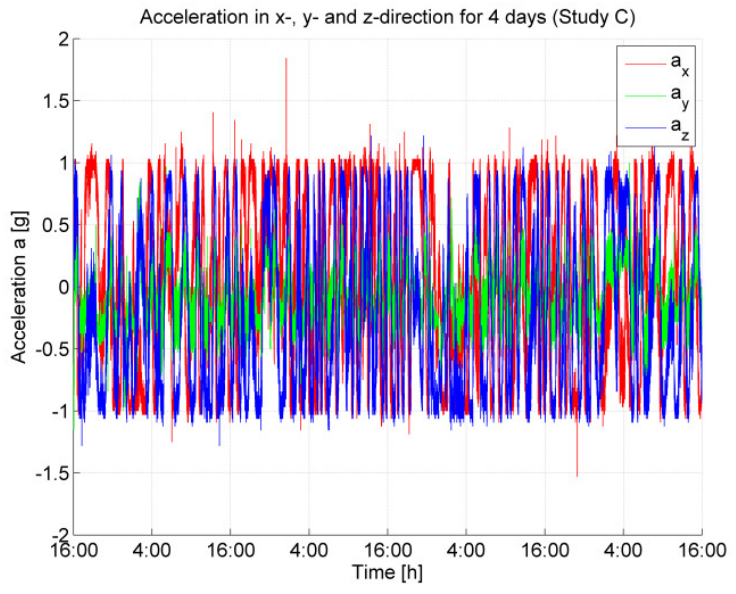

Image 8 Measurements of the acceleration study C (4 days)

In the images 9, 10 and 11 generator discharges and the resulting power output are shown during the acceleration measurement.

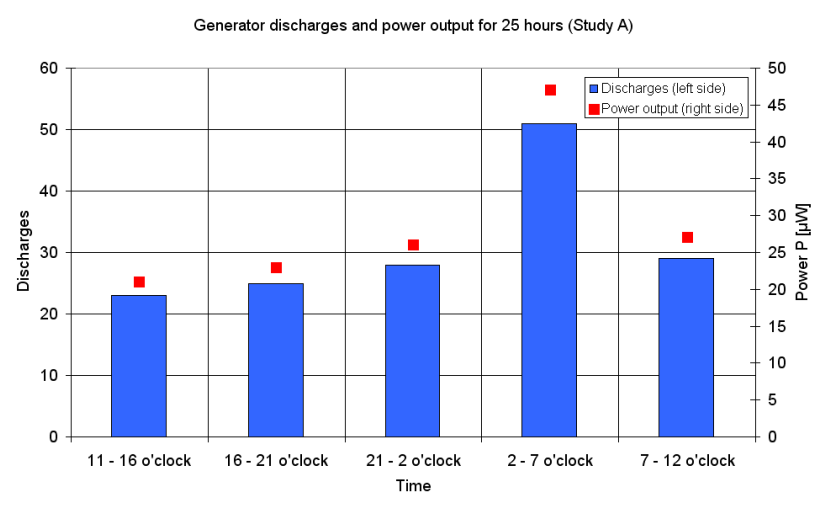

Image 9 Generator discharges and power output study A (25h)

During the experiments, 7 discharges per hour (study A), 6 discharges per hour (study B) and 3 discharges per hour (study C) could be registered by the energy generator. This corresponded to a continuous power output of $6 \mu \mathrm{W}$ (study A), $5 \mu \mathrm{W}$ (study B) and $2.8 \mu \mathrm{W}$ (study C).

From the detected generator discharges the activity of the animal can be derived. In comparison to the remaining day segments, particularly in the morning hours between 4 and 9 o'clock the highest generator discharges were detected. 


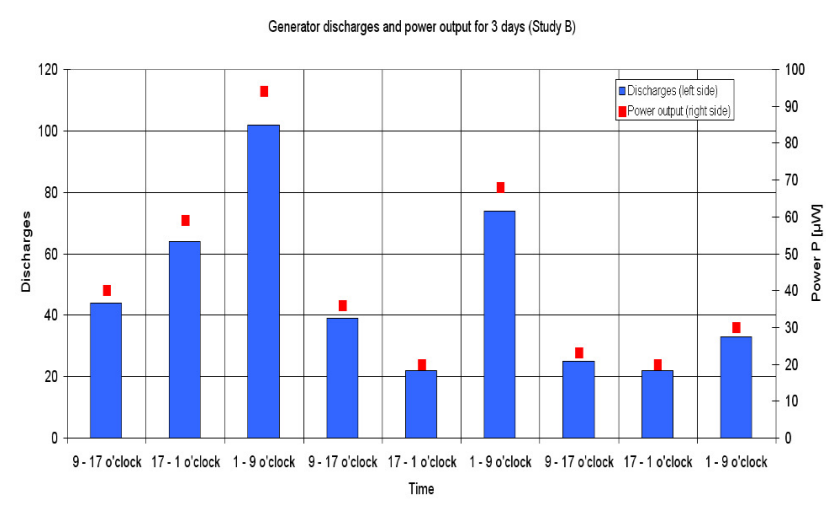

Image 10 Generator discharges and power output study B (3 days)

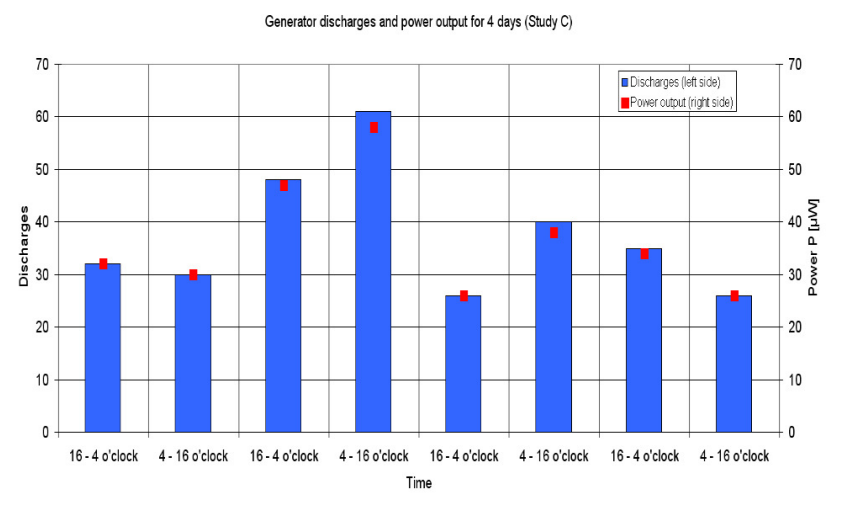

Image 11 Generator discharges and power output study C (4 days)

\section{Conclusion}

With the newly developed energy generator, power outputs could be generated in $\mu \mathrm{W}-$ range. The harvested energy can support sensor and telemetry systems, which contributes to the monitoring of the ruminal $\mathrm{pH}$ - value of cattle. The aim of future works is the advancement and optimisation of the energy generator as well as the investigation of the acceleration appearing in different ruminal layers.

\section{$5 \quad$ References}

[1] Reuter T., Liebold S., Hoffmann M., Schmidt S., Bartsch T., Hörschelmann P., Weisheit E.: Test of a Generator for the Energy Supply of Biosensors for the Application on Human and Animal Subjects., Biomedical Engineering, Vol.56, ISSN 0939-4990,

Tagungsband BMT 2011, 27-30.09.2011.

[2] Kanoun Olfa, Wallaschek Jörg: Energy Harvesting: Grundlagen und Praxis energieautraker Systeme. Haus der Technik Fachbuch Band 92, 2008. ISBN: 978-38169-2789-1.

[3] Mateu Loreto, Moll Francesc: Review of Energy Harvesting Techniques and Applications for Microelec- tronics, Proceedings of the SPIE Microtechnologies for the New Millenium, 2005.

[4] Engelhardt, W.v. und G. Breves (Hrsg.): Physiologie der Haustiere. 15.Physiologie des Magen-DarmKanals, Enke-Verlag, Stuttgart, 2.Aufl. 2000, S. 313422. ISBN: 3-8304-1039-5.

[5] Hoffmann, R. R. und B. Schnorr: Die funktionelle Morphologie des Wiederkäuermagens. Enke-Verlag, Stuttgart 1982, ISBN: 3-432-88081-2.

[6] Dirksen G., Gründer H.-D. und Stöber M.: Die klinische Untersuchung des Rindes, Enke-Verlag, Stuttgart, 4.Aufl. 2012, S. 305. ISBN: 978-3-8304-1211-3.

Acknowledgement: Funded by the German Ministry for Economics and Technology following a decision of the German Bundestag. Reg.-Nr. KF2058703KM9.

The authors would like to thank the veterinary clinic of the FZMB GmbH for assisting the experiments and Ms. Nastja Rebrin for translating works. 